STUDIA UBB PSYCHOL.-PAED., LXVI, 1, 2021, p. 5 - 36

(Recommended Citation)

DOI:10.24193/subbpsyped.2021.1.01

\title{
EXPLORING AGE AND GENDER DIFFERENCES IN NARCISSISM AND PERFECTIONISM AND THEIR MENTAL-HEALTH CORRELATES
}

\author{
ÉVA KÁLLAY ${ }^{1}$ and ALEXANDRA REBECA MIHOC ${ }^{2}$
}

\begin{abstract}
The changes occurring in modern society can significantly influence individuals' well-being, mental health and even personality traits such as narcissism and perfectionism. Since studies investigating age and gender differences in narcissism and perfectionism have produced mixed results, and the number of studies conducted in Romanian population is scarce, the main aims of this study were to investigate possible age and gender differences in narcissism, perfectionism and several mental-health indicators in a sample of healthy participants, as well as specific association patterns between these variables within each group of participants. Our sample included 465 millennials and 149 participants over 35 years of age. The results indicate that millennials reported significantly lower levels of narcissism and self-oriented perfectionism than the older generations, higher levels of depressive symptoms and lower levels of autonomy, environmental mastery, purpose in life, and self-acceptance. Female millennials reported lower levels of narcissistic traits and higher levels of socially-prescribed perfectionism, depressive symptoms, personal growth, and positive relations with others than male participants. Older females indicated significantly higher levels of depressive symptoms and loneliness than male participants. Regarding association patterns, in the group of millennial women narcissism was positively correlated with self-oriented, socially-prescribed perfectionism and subjective well-being, and negatively with loneliness, environmental mastery and purpose in life. In millennial males, we found significant positive correlations only between narcissism and subjective wellbeing and environmental mastery. Our findings may have important implications for the literature regarding millennials and can contribute to the interventions and prevention programs designed to improve their well-being.
\end{abstract}

Keywords: millennials, narcissism, perfectionism, mental health indicators, age and gender differences

1 Department of Psychology, Babes-Bolyai University, Cluj-Napoca, Romania

2 Department of Sociology, Babes-Bolyai University, Cluj-Napoca, Romania

* Corresponding author: evakallay@psychology.ro 
ÉVA KÁLLAY, ALEXANDRA REBECA MIHOC

\section{Introduction}

Presently, we live in a society which some sociologists call the late or liquid modernity (Bauman, 2007), characterized by intense feelings of uncertainty determined by the frequent changes in life-style, working style, basic value systems, long-term goals or ways in which we can achieve happiness, etc. Society intensely 'recommends' people to assert their individuality, however, in this process of individuation the individual moves away from the traditional, more group-centered ways of living, simultaneously losing a very important source of support (Bauman, 2000). Briefly put, today's adult life requires one to face a much greater number of challenges than the adult lives of past generations (Goodman, Schlossberg, \& Anderson, 2006), especially on the younger generations (Oeppen \& Vaupel, 2002; Robinson \& Godbey, 1999; Roser, 2020). The Millennials (born 1985-1999) (Fry, 2018; Martin, 2018) for example, have to face challenges that previous generations did not encounter: instability in the workplace, financial insecurities, changes in values systems, less stable relationships, growth of income inequity, social media consumption, changes in personality traits, increase in the type of daily stressors - all of these factors may negatively impact the wellbeing of present generations etc. (Oishi, Kesebir, \& Diener, 2011; Twenge \& Kasser, 2013; Banyard, Edwards, \& Kendall-Tackett, 2009; Curran \& Hill, 2017). In addition to all these changes, younger people are subject to increasing external pressures, are urged to compete against each other, to constantly excel, and to achieve perfection (Curran \& Hill, 2017; Twenge, 2014; Collishaw, Gardner, Maughan, Scott, \& Pickles, 2012; Verhaeghe, 2014).

Not surprisingly, in the same time a growing tendency of mental health problems was noticed (depression, anxiety disorders, loneliness, etc.). This phenomenon happens even if increasingly larger number of people started reporting symptoms, the popularization of mental health problems increased, stigma got significantly reduced, criteria in diagnostic manuals have changed (Collins, Patel, Joestl, March, Insel \& Daar, 2011; Erzen \& Çikrikçi, 2018; Hawkley \& Cacioppo, 2010; Perissinotto, Stijacic Cenzer, \& Covinsky, 2012; Victor \& Bowling, 2012; WHO, 2017). Anxiety and depression are among the most common mental health issues, statistics showing that in 2017 over 264 million people suffered from anxiety (i.e., over 3.4\% of the world's population) and over 298 million people from depressive symptoms (i.e., over $4.4 \%$ of the population of the world) (Ritchie \& Roser, 2018: WHO, 2017). According to scientific predictions, by 2030 depression will become the second most serious illness worldwide, significantly affecting the suffering individuals' personal and professional life, simultaneously representing significant socio-economic burdens as well (Gustavsson et al., 2011; Wittchen et al., 2011). Recent studies indicate that 
these results are valid for the millennials as well, affecting more seriously the female, than the male millennials, since they are more at risk for mental ill-health than males (Bor, Dean, Najman, \& Hayatbakhsh, 2014; Patalay \& Fitzsimons, 2017; Patalay \& Gage, 2019).

Moreover, related to the growing tendencies of depression and anxiety, in the last decades an increasing number of people worldwide reported significant levels of loneliness, constellation of reactions and states that are strongly associated with depression and anxiety (Cacioppo \& Patrick, 2008; Erzen \& Çikrikci, 2018). Contrary to expectations, high levels of loneliness were reported by young adults and children as well (e.g., Cigna U.S. Loneliness Index, 2018; Perlman, 1990; Pinquart \& Sorensen, 2003; Qualter et al., 2015). All these negative changes in mental health may significantly impact individuals' subjective and psychological well-being regardless of age (Yang, 2008; Moirangthem \& Panda, 2018).

\section{Narcissism and Perfectionism}

With the beginning of the $21^{\text {st }}$ century, investigations conducted by different groups of researchers indicated increases in narcissism, especially among youth (Twenge, 2006; Twenge \& Campbell, 2008). Twenge and colleagues' (Twenge, Campbell, \& Freeman, 2012; Twenge, Campbell, Hoffman, \& Lance, 2010) repeatedly found that within the category of narcissistic traits young adults tend to exhibit increased: positive self-view, interest in leisure, extrinsic goal orientation, vocational orientation mostly towards financial benefits and less towards real interest, reduction of the interest in environment and civic activities, significant increases in psychopathology, etc. Moreover, recent generations of college students were also found to report higher levels of extraversion and self-confidence than previous generations (e.g., Curran \& Hill, 2017; Twenge, 2001a; Twenge, Campbell, \& Gentile, 2012; Twenge, Konrath, Foster, Campbell, \& Bushman, 2008). Recent studies regarding age and gender differences in narcissism traits show mixed results. According to Foster, Twenge, and Campbell's (2003) study and recent two meta-analyses (Twenge, Freeman, \& Campbell, 2012; Twenge et al., 2008), generational differences predicted more narcissism in younger people, who grew up in eras characterized by high levels of individualism (Lasch, 1979; Twenge \& Campbell, 2001). On the other hand, other groups of investigators have come up with studies that sustain that there would be very little evidence regarding a generational increase in narcissism (Arnett, 2013; Trzesniewski, Donnellan, \& Robins, 2008a; Trzesniewski, Donnellan, \& Robins, 2008b). The debate regarding this issue is still going on - mostly due to 
methodological issues (mainly cross-sectional studies) it is not yet clear if the age-related differences in narcissistic traits are the result of period, cohort, developmental, cultural effects, or a combination of them (Paulsen, Trzesniewski, \& Syed, 2015). Regarding gender differences, few studies have provided an integrative evaluation of the nature of sex differences in narcissism, a recent meta-analysis showing that men are more narcissistic than women, but the overall size-effect is debatable and not conclusive (Grijalva et al., 2015).

According to DSM-5, clinical manifestations of narcissism are represented by a "pervasive pattern of grandiosity (in fantasy or behavior), a constant need for admiration, and a lack of empathy" (American Psychiatric Association, 2013, p. 669). Raskin and Hall's (1979) conceptualization is derived from social psychology, where narcissism is conceptualized as a personality trait, a concept different from that of Narcissistic Personality Disorder. Narcissistic traits encompass characteristics such as: entitlement, frequent need for validation, grandiose sense of self-importance and superiority, justification, high selfesteem, tendency to exploit interpersonal relationships for own purpose, great emphasis on social status, permanent comparison with others, envy and the feeling that one is envied, sensitivity to criticism, reduced capacity of selfreflection, arrogance, etc. (Paulhus \& Wiliams, 2002).

There is a heated debate in literature regarding the (mal)adaptational values of narcissism. Some approaches consider narcissistic traits on a continuum with healthy and pathological forms situated on the extreme ends (Pincus \& Lukowitsky, 2010). Depending on the prevalence, intensity and frequently of symptoms, some characteristics of narcissism have proved to be adaptive in specific contexts and situations, while others maladaptive (Hill \& Lapsley, 2011; Paulsen et al., 2015). A plethora of studies indicated that narcissistic traits, especially its adaptive forms, are positively associated with self-esteem (Sedikides, Rudich, Gregg, Kumashiro, \& Rusbult, 2004), subjective well-being (Egan, Chan, \& Shorter, 2014; Jonason, Baughman, Carter, \& Parker, 2015), and optimism (Hickman, Watson \& Morris, 1996) and are negatively associated with depressive symptoms, and experiences of daily and dispositional loneliness (Sedikides et al., 2004).

Simultaneously, research indicated that perfectionism has also increased worldwide in the last decades (Curran \& Hill, 2017). A possible motive proposed by different researchers traces these modifications back to cultural factors and changes in modern culture, which cannot be attributed to genetic factors (Klerman \& Weismann, 1988; Twenge, 2011). According to Curran and Hill's (2017) study, just as culture produces individual differences between countries, the culture of different time-periods may also produce generational differences in personality traits. 
Cultural values in the western society (individualism, materialism, consumerism) have undergone a remarkable change in recent decades, negatively influencing two somewhat interrelated aspects of malfunctioning - narcissism and maladaptive perfectionism (Curran \& Hill, 2017; Markus \& Kitayama, 1991; Twenge \& Campbell, 2009; Verhaeghe, 2014). Recent studies have investigated the dimensions of trait perfectionism and their relationship with narcissism (Flett, Sherry, Hewitt, \& Nepon, 2014). Perfectionism represents a central feature of narcissism, mirroring its characteristic ways of thinking, behaving, relating and feeling (Beck, Freeman, \& Davis, 2004; Rothstein, 1999). Empirical studies show that narcissism and perfectionism are moderately correlated, this relationship being generalized in both genders (Hewitt et al., 2003; Sherry et al., 2014). Perfectionism is usually defined as the tendency to strive toward personal improvement and to set excessively high standards for oneself (Short \& Mazmanian, 2013). As in the case of narcissism, literature indicates that perfectionism has both positive, adaptive forms which lead to tangible benefits (i.e., higher levels of accomplishment) (Hewitt, Flett, \& Mikail, 2017), and maladaptive variations, which are considered factors of vulnerability in terms of personality characteristics (Hewitt et al., 2017). People characterized by excessively high levels of perfectionism impose unrealistic standards both themselves or for those around them. Consequently, they may end up overreacting to failure, to encountered problems or stressful situations (Hewitt et al., 2017). Hewitt and Flett (1991) conceptualized perfectionism as a multidimensional construct, and distinguishes between self-oriented perfectionism, other oriented perfectionism, and socially prescribed perfectionism (Hewitt \& Flett, 1991). The main difference between the three dimensions of the model consists in the object towards which the attitudes and the perfectionist behavior are directed (Hewitt \& Flett, 1991).

Self-oriented perfectionism (SOP) is characterized by setting exceptionally high standards and unrealistic goals for the self, completed with critical selfevaluation. SOP contains the belief that striving for perfection and being perfect are extremely important (Hewitt \& Flett, 1991; Stoeber, 2015; Curran \& Hill, 2017). This dimension also has an important motivational component, which directs the individual to achieve perfection and to avoid failure. Studies show that SOP is often associated with achievement-related behaviors (Hewitt \& Flett, 1991), however it can also become a vulnerability factor in situations when the individual relates his/her self-worth to personal achievements. Studies show that SOP is also positively associated with greater psychological reactivity, clinical depression, anorexia nervosa, suicidal ideation, and negative affect in general (Hewitt \& Flett, 1991, 1993; Besser, Flett, \& Hewitt, 2004; Besser, Flett, Hewitt, \& Guez, 2008; Enns \& Cox, 2005; Fry \& Debats, 2009). 
Persons scoring high on Other-oriented perfectionism (OOP) are characterized by having unrealistic expectations from others, combined with a highly critical evaluation of those who fail to meet these expectations. When significant others cannot meet the required standards, they end up being blamed, criticized and even treated with hostility by persons high on OOP (Hewitt \& Flett, 1991; Stoeber, 2015 Hewitt, Flett, \& Mikail, 2017). Compared to the other dimensions of perfectionism, OOP is more evident in interpersonal behaviors. Literature indicates that $\mathrm{OOP}$ is frequently associated with negative interpersonal traits such as lower agreeableness, neuroticism, narcissism, arrogance and vindictiveness (Hewitt \& Flett, 1991; Hill, Mcintire, \& Bacharach, 1997; Hill, Zrull, \& Turlington, 1997; Smith, et al., 2016). In addition, due to exaggerated demands and expectations from others, OOP is linked to lower levels of altruism, trust and compliance (Hewitt \& Flett, 1991; Hill, McIntire, \& Bacharach, 1997; Hill, Zrull, \& Turlington, 1997).

Socially prescribed perfectionism (SOP) involves the belief that the social context or significant others are excessively demanding, have unrealistic standards and expectations, judge harshly, and put pressure on one being perfect (Hewitt \& Flett, 1991; Curran \& Hill, 2017). A person with a high level of SPP perceives that the standards imposed by others are exaggerated and uncontrollable, and the inability to achieve them often leads to intense emotional states such as anxiety, anger or depression (Sherry, Hewitt, Flett, \& Harvey, 2003; Smith et al., 2016). Literature indicates that socially prescribed perfectionism is the most debilitating of the three dimensions of perfectionism, longitudinal and experimental studies showing its positive associations with various forms of major psychopathology (e.g., anxiety, depression) and even suicidal ideation (Martin, Flett, Hewitt, Krames, \& Szanto, 1996; Hewitt, Flett, \& Weber, 1994; Sherry, et al., 2003; Smith et al., 2016).

Research indicates there is an association of moderate intensity between narcissism and multidimensional perfectionism, the association appearing in both genders (Hewitt et al., 2003; Sherry et al., 2014). Furthermore, in most studies, narcissism has been positively correlated with both SOP and SPP, but in terms of OOP, studies are inconsistent, showing mixed results (Trumpeter, Watson, \& O'Leary, 2006; Flett, Sherry, Hewitt, \& Nepon, 2014; Smith et al., 2016). However, even in the light of these data, the relationship between narcissism and perfectionism remains complicated, the explanations regarding the causality between the two is in need of clarification. 
EXPLORING AGE AND GENDER DIFFERENCES IN NARCISSISM AND PERFECTIONISM AND THEIR MENTAL-HEALTH CORRELATES

\section{Well-being}

In recent decades, the issue of well-being has gained more and more attention in the social and behavioral sciences and especially in psychology (Ryan \& Deci, 2001). The World Health Organization defines health as "a state of complete physical, mental and social well-being and not merely the absence of disease or infirmity" (WHO, 2018). Researchers claim that well-being is a multidimensional concept, composed by both elements of the subjective (hedonic) and psychological (eudaimonic) approaches (King \& Napa, 1998; McGregor \& Little, 1998). The hedonic approach defines well-being in terms of pleasure and happiness attainment and pain avoidance (Kahneman, Diener \& Schwartz, 1999). The main indicator used for this approach is the subjective well-being (SWB) which refers mostly to positive self-evaluation of one's life (Diener, 1984; Andrews \& Robinson, 1991; Ryan \& Deci, 2011). The eudaimonic approach, on the other hand goes beyond mere pleasure, sustaining that wellbeing is mostly represented by finding meaning, purpose and realization of one's true potential (Ryff, 1989; Ryff \& Keyes, 1995).

Ryff and Singer (1998, 2000, 2006) conceptualized psychological wellbeing (PWB) as consisting of six different components:

1. self-acceptance- involves a positive attitude towards oneself and acceptance of all aspects of the self, both good and bad qualities along with acceptance of personal past. This dimension of non-judgmental acceptance of one's self together is considered as one of the fundamental aspects of mental health and optimal functioning.

2. positive relations with others- this dimension refers to the development and maintenance of warm, satisfying, and trusting relations with others, care for the welfare for others and appreciation for human relationships. This dimension was found to be related to empathy, affection and intimacy proving to be a protective factor in confrontation with adversity.

3. autonomy-requires a sense of self-determination and the ability to think and behave in specific ways to resist social pressures. People with a high level of autonomy regulate their own emotions and behavior according to their own standards and evaluate themselves according to their own opinions.

4. environmental mastery- involves the ability to effectively navigate one's life and the surrounding environment, and the ability to establish contexts that are relevant to one's needs and values. The individual is able to control his/her external environment in order to adapt and function better (Ryff, 1989). 


\section{ÉVA KÁLLAY, ALEXANDRA REBECA MIHOC}

5. purpose in life- it refers to the feeling that there is meaning and purpose in present and past life. The individual has an aim for living, thus sustaining a creative and productive life. Literature indicates that meaning and purpose in life contribute to the maintenance of mental and physical health (Hill \& Turiano, 2014; Boyle, Barnes, Buchman, David, \& Bennett, 2009).

6. personal growth-refers to people's need for self-actualization through continuous development, growth, experiences and realization of the one's true potential. This dimension of psychological well-being is closest to Aristotle's approach to eudaimonia and is strongly associated to mental health and flourishing (Ryff, 1989).

Many studies in this field have attempted to identify factors that are associated and may affect well-being, as: age, wealth, satisfaction with income, relationship status, social support networks, personality factors, adaptive emotion regulation strategies etc. (Diener, Gohm, Suh, \& Oishi, 2000; Folkman \& Moskowitz, 2004; Diener, Lucas, \& Oishi, 2002; Chang \& Farrehi, 2001). Regarding personality factors, maladaptive forms of narcissism and perfectionism were found to be associated with more intense psychological symptoms, including depression, anxietyand loneliness (Frost, Marten, Lahart, \& Rosenblate, 1990; Chang, Sanna, Chang, \& Bodem, 2008; Wang, Yuen, \& Slaney, 2008; Gnilka, Ashby, \& Noble, 2012; Carter \& Douglass, 2018). In the case of narcissism, the results are mixed, with some studies showing positive associations between narcissism and happiness, while/and others emphasized that narcissism is associated with some indicators of psychological well-being (Kohut, 1977; Rhodewalt, Madrian, \& Cheney, 1998; Rhodewalt \& Morf, 1995; Watson, Hickman, \& Morris, 1996; Watson, Little, Sawrie, \& Biderman, 1992; Rose, 2002; Egan, Chan, \& Shorter, 2014). Also, three dimensions of psychological well-being, namely, autonomy, environmental mastery and purpose in life are associated with socially-prescribed perfectionism (Chang, 2006).

\section{Objectives}

Literature indicates that psychopathology may vary depending on the individual's personality traits (Widiger, 2011), namely, different personality factors may have a strong relationship with symptoms of psychopathology (Papageorgiu, Denovan, \& Dagnall, 2019). Lately, one of the topics of major interest in this area has been the investigation of the relationship between narcissism and mental health indicators, especially depression. This far, the 
EXPLORING AGE AND GENDER DIFFERENCES IN NARCISSISM AND PERFECTIONISM AND THEIR MENTAL-HEALTH CORRELATES

synthesis of extant research indicates somewhat mixed results, some investigations reporting a positive association between pathological narcissism and depression (Kealy, Laverdière, \& Pincus, 2020), while other studies consider that narcissistic traits may encompass adaptive behaviors that might guard the person from the development of depression (e.g., Veselka, Schermer, \& Vernon, 2012). Furthermore, literature also indicates that perfectionism is a central feature of narcissism (Ronningstam, 2010, 2011), and is a strong predictor of depression (Hewitt, Flett, \& Ediger, 1996). Unfortunately, based on demographic variables, literature offers mixed results regarding the groups of populations that are highest at risk for developing maladaptive forms especially in relation to narcissism and perfectionism. Some studies indicate that younger generations present higher levels of narcissism, with narcissistic traits decreasing over time (Foster, Campbell, \& Twenge, 2003, Roberts, Edmonds, \& Grijalva, 2010), while other studies sustain that there is no direct evidence for such claims (Arnett, 2013; Trzesniewski, Donnellan, \& Robins, 2008a; Trzesniewski, Donnellan, \& Robins, 2008b; Twenge, Campbell, \& Freeman, 2012; Twenge, Campbell, Hoffman, \& Lance, 2010). Furthermore, besides systematically recorded differences in depression between men and women, literature has no stable results indicating similar gender-related differences in narcissism and perfectionism (Sherry et al., 2014).

Since these relationships are under studied in the Romanian population, our study has two major aims, to investigate:

(1) possible age and gender differences in narcissism, perfectionism and mental-health indicators (depression, happiness, loneliness and psychological well-being) in a sample of healthy participants.

(2) specific association patterns between narcissistic traits, perfectionism and mental health indicators (depressive symptoms, loneliness, happiness and psychological well-being) within each group of participants (age millennials and above 35 years of age, and gender).

\section{Study}

\section{Participants}

Our study included 614 participants, 465 millennials (under 35 years of age) and 149 participants over 35 years of age. Mean age in the millennial's group was: 22.36 years ( $\mathrm{SD}=3.77$ ), and in the group of older generation 46.56 ( $S D=7.18)$. Of the millennial-group 373 were female and 94 male participants, 
and in the group with ages over 35 years, 94 were females and 55 males. All participants resided Transylvania, the Western part of Romania. After providing informed consent, participants completed either online questionnaire packets that took 45 minutes to fill, or were evaluated in a face-to-face assessment session with the researcher. Data collection started in September 2019 and ended in December 2019. In order to be able to collect as many data as possible, some of the participants who were available were assessed in a face to face session, while those who were not available, were assessed with an online questionnaire. Participation was voluntary.

\section{Instruments}

Demographic variables were: age and gender.

Depression tendencies were measured with the Beck Depression Inventory-II (BDI, Beck, Rush, Shaw \& Emery, 1979; Romanian adaptation David \& Dobrean, 2012). The BDI is a 21-item, multiple-choice format inventory, designed to measure the presence of depression in adults and adolescents. Each of the 21 items assesses a symptom or attitudes specific to depression, inquiring its somatic, cognitive and behavioral aspects. By its assessments, single scores are produced, which indicate the intensity of the depressive episode. Internal consistency indices of the BDI are usually above .90. For the present sample, the internal consistency indices for the BDI was .88.

Subjective-well-being was measured with the 29-item Oxford Happiness Questionnaire (OHQ) (Hills \& Argyle, 2002; translated and adapted into Romanian by the authors). The OHS measures happiness as a unidimensional compact construct. Examples of items: "Life is good", "I am very happy", "I often experience joy and elation". The has 29 items, with 12 reverted items, using a Likert scale with answers from 1 to 6 ( $1=$ strongly disagree, to $6=$ strongly agree). The psychometric properties of OHQ are very good (Cronbach $\alpha=.90$ ).

Loneliness and perceived social isolation was measured with the 20item UCLA Loneliness Scale (revised UCLA Loneliness Scale; Russell, Peplau, \& Cutrona, 1980; translated and adapted into Romanian by the author). Participants are asked to respond to each item on a 4-point Likert scale, from 'never' to 'always'. The scale's items are worded to suggest a general, present-day experience that relate to both social and emotional dimensions of loneliness (e.g., "No one really knows me well"; "My interests and ideas are not shared by those around $m e$ ", and "I feel in tune with the people around me"). The UCLA Loneliness Scale consists of both positively and negatively worded items, with a possible total score 
of 20 to 80 points with no identified cut-off score that would define loneliness. The scale has good internal consistency with a Cronbach's $\alpha$ of 0.94 (Russell et al., 1980). Mean scores for university students usually vary between 36 and 39 (Anderson, Miller, Riger, Dill, \& Sedikides, 1994).

Narcissistic traits were measured with 16-item Narcissistic Personality Inventory (NPI-16, Ames, Rose, \& Anderson, 2006; translated and adapted into Romanian by the author) derived by the authors from the long, 40 -item NPI scale (Raskin \& Hall, 1979). Examples of items: "I really like to be the center of attention", "It makes me uncomfortable to be the center of attention". The test consists of sixteen pairs of statements, and for each pair subjects should select the one that they feel best reflect their personality. The NPI-16 is a short measure of subclinical narcissism, presenting a good face, internal, discriminant, and predictive validity (Ames et al., 2006). The internal consistency of the NPI16 for the present sample was .82 .

Perfectionism was measured with the 45-item self-report Multidimensional Perfectionism Scale (MPS, Hewitt \& Flett, 1991; translated and adapted into Romanian by the author). The MPS contains three sub-scales: self-oriented perfectionism (SOP) (e.g., "One of my goals is to be perfect in everything I do"), other-oriented perfectionism (OOP) (e.g., "Everything that others do must be of top-notch quality"), and socially-prescribed perfectionism (SPP) (e.g., "I find it difficult to meet others' expectations of me"). Responses are given on a 7-point Likert scale, from 1 (strongly disagree) to 7 (strongly agree). The psychometric properties of the scale (reliability and validity) were found across studies to be very good (Hewitt et al., 2003). Cronbach's alpha for the present sample ranged from .73 to .89 .

Psychological well-being was measured by the 44-item scale developed by Ryff (1989) and adapted into Romanian by Kállay and Rus (2014). This scale has 6 sub-scales measuring the basic components of eudaimonic well-being: self-acceptance (PWB-SA), positive relations with others (PWB-PRO), autonomy (PWB-A), environmental mastery (PWB-EM), purpose in life (PWB$\mathrm{PL}$ ), and personal growth (PWB-PG). Items are assessed along a 6-point scale, $1=$ total agreement, and $6=$ total disagreement. Examples of items: "In general, I feel I am in charge of the situation in which I live", "I have a sense of direction and purpose in life.". The psychometric properties of the Romanian translation are good (.81-.88). On each sub-scale high scores mean high WB, while low scores mean low levels of psychological well-being. The internal consistency of the Psychological Well-being scale for the present sample ranged from .81. 
ÉVA KÁLLAY, ALEXANDRA REBECA MIHOC

\section{Results}

Data were analyzed with IBM SPSS Statistics 20. After cleaning the data base, we run statistical tests to identify descriptive characteristics of the sample. Firstly, we present the descriptive characteristics of our data (see Table 1).

Table 1. Descriptive statistics

\begin{tabular}{lccccccc}
\hline & N & Min. & Max. & Mean & SD & Shapiro-Wilk & p \\
\hline NPI & 614 & 0 & 16 & 8.30 & 5.09 & .92 & .000 \\
\hline MPS SOP & 609 & 24 & 103 & 64.43 & 12.98 & .99 & .013 \\
\hline MPS 00P & 611 & 30 & 102 & 59.97 & 9.80 & .98 & .000 \\
\hline MPS SPP & 612 & 29 & 95 & 62.89 & 11.41 & .99 & .243 \\
\hline BDI & 593 & 0 & 44 & 10.00 & 8.47 & .91 & .000 \\
\hline UCLA & 613 & 23 & 79 & 51.50 & 7.66 & .93 & .000 \\
\hline OXFORD & 609 & 49 & 164 & 108.32 & 15.08 & .97 & .000 \\
\hline PWB AUT & 614 & 12 & 42 & 32.03 & 6.13 & .97 & .000 \\
\hline PWB PG & 614 & 8 & 48 & 35.27 & 7.19 & .96 & .000 \\
\hline PWB PRO & 615 & 10 & 54 & 45.63 & 6.49 & .92 & .000 \\
\hline PWB PL & 614 & 7 & 101 & 32.67 & 7.32 & .98 & .000 \\
\hline PWB SA & 615 & 7 & 42 & 31.59 & 7.01 & .95 & .000 \\
\hline
\end{tabular}

Note: NPI-16=Narcissistic traits, MPS-SOP=Multidimensional Perfectionism-Self-Oriented-Perfectionism, MPS-OOP=Multidimensional Perfectionism-Other-Oriented-Perfectionism, MPS-SPP=Socially-Prescribed Perfectionism, BDI - Beck Depression Inventory, UCLA-Loneliness scale, Oxford = Happiness Scale, PWB$A U T=$ Psychological Well-Being - Autonomy, $P W B$-EM =Psychological Well-Being - Environmental Mastery, $P W B-P G=$ Psychological Well-Being - Personal Growth, $P W B-P G=$ Psychological Well-Being Positive Relations with Others, $P W B-P L=$ Psychological Well-Being - Purpose in Life, $P W B-S A=$ Psychological Well-Being - Self-Acceptance

Next, we continued our analysis by comparing the assessed variables depending on the two age groups, namely participants born before and after 1985 (Group 1 - before 1985, Group 2 - Millennials). Since our data did not follow a normal distribution (see Table 1), we opted for non-parametric analyses, and effect sizes were calculated according to the formula: $\mathrm{r}=\mathrm{Z} / \sqrt{\mathrm{N}}$. Significant differences are presented in Table 2. 
EXPLORING AGE AND GENDER DIFFERENCES IN NARCISSISM AND PERFECTIONISM AND THEIR MENTAL-HEALTH CORRELATES

Table 2. Significant differences between millennials (group 1 - younger than 35 years of age) and participants older than 35 years of age (group 2) in narcissism, multidimensional perfectionism, depressive symptomatology, loneliness, happiness, and components of psychological well-being

\begin{tabular}{|c|c|c|c|c|c|c|}
\hline SCALES & Group & Mean & SD & $\mathbf{Z}$ & $p$ & $r$ \\
\hline \multirow[t]{2}{*}{ NPI-16 } & $\operatorname{Gr} 1(N=464)$ & 8.06 & 5.10 & -4.43 & .000 & 0.18 \\
\hline & $\mathrm{Gr} 2(\mathrm{~N}=149)$ & 10.19 & 4.71 & & & \\
\hline \multirow[t]{2}{*}{ MPS_SOP } & $\mathrm{Gr} 1(\mathrm{~N}=464)$ & 64.65 & 12.51 & -2.90 & .004 & 0.12 \\
\hline & $\operatorname{Gr} 2(N=149)$ & 68.64 & 13.98 & & & \\
\hline \multirow[t]{2}{*}{ MPS_0OP } & $\operatorname{Gr} 1(N=464)$ & 59.11 & 9.07 & -3.34 & .001 & 0.13 \\
\hline & Gr2 (N=149) & 62.97 & 11.67 & & & \\
\hline \multirow[t]{2}{*}{ BDI } & $\mathrm{Gr} 1(\mathrm{~N}=464)$ & 10.66 & 8.53 & -4.48 & .000 & 0.18 \\
\hline & $\operatorname{Gr} 2(N=149)$ & 7.39 & 7.44 & & & \\
\hline \multirow[t]{2}{*}{ PWB-AUT } & $\mathrm{Gr} 1(\mathrm{~N}=464)$ & 31.50 & 6.23 & -4.43 & .000 & 0.18 \\
\hline & $\mathrm{Gr} 2(\mathrm{~N}=149)$ & 34.01 & 5.45 & & & \\
\hline \multirow[t]{2}{*}{ PWB-EM } & $\operatorname{Gr} 1(N=464)$ & 35.27 & 7.08 & -5.59 & .000 & 0.23 \\
\hline & Gr2 (N=149) & 38.67 & 6.78 & & & \\
\hline \multirow[t]{2}{*}{ PWB-PL } & $\operatorname{Gr} 1(N=464)$ & 32.19 & 6.85 & -3.57 & .000 & 0.14 \\
\hline & $\operatorname{Gr} 2(N=149)$ & 34.88 & 7.99 & & & \\
\hline \multirow[t]{2}{*}{ PWB-SA } & $\mathrm{Gr} 1(\mathrm{~N}=464)$ & 31.43 & 6.95 & -2.31 & .021 & 0.09 \\
\hline & Gr2 (N=149) & 32.83 & 6.88 & & & \\
\hline
\end{tabular}

Note: NPI-16=Narcissistic traits, MPS-SOP=Multidimensional Perfectionism-Self-Oriented-Perfectionism, MPS-OOP=Multidimensional Perfectionism-Other-Oriented-Perfectionism, BDI - Beck Depression Inventory, $P W B-A U T=$ Psychological Well-Being - Autonomy, $P W B$-EM $=$ Psychological Well-Being Environmental Mastery, $P W B-P L=$ Psychological Well-Being - Purpose in Life, $P W B-S A=$ Psychological Well-Being - Self-Acceptance

Our results indicate that millennials reported a significantly lower levels of narcissism $(Z=-4.43, p<.001)$, self-oriented $(Z=-2.90, p<.01)$ and other oriented perfectionism $(\mathrm{Z}=-3.34, p<.001)$ than the older generation, with rather low effect sizes ( $\mathrm{r}=0.18,0.12,0.13)$. Regarding mental health indicators, millennials reported significantly higher levels of depressive symptoms than the older generation $(\mathrm{Z}=-4.48, p<.001)$, and lower levels of psychological wellbeing on the following dimensions: autonomy $(Z=-4.43, p<.001)$, environmental mastery $(\mathrm{Z}=-5.59, p<.001)$, purpose in life $(\mathrm{Z}=-3.57, p<.001)$, and self-acceptance $(Z=-2.31, p<.001)$. In these cases, too, effect sizes were small (see Table 2$)$. 
We continued our investigation with investigating possible gender differences between the two gender groups, on the same variables. Results are presented in Table 3.

Table 3. Significant differences between female and male participants in narcissism, multidimensional perfectionism, depressive symptomatology, loneliness, happiness, and components of psychological well-being

\begin{tabular}{|c|c|c|c|c|c|c|}
\hline SCALES & Group & Mean & SD & $\mathbf{Z}$ & $p$ & $r$ \\
\hline \multirow[t]{2}{*}{ NPI-16 } & $\mathrm{F}(\mathrm{N}=467)$ & 8.15 & 5.23 & -3.31 & .001 & 0.13 \\
\hline & $\mathrm{M}(\mathrm{N}=147)$ & 9.88 & 4.36 & & & \\
\hline \multirow[t]{2}{*}{ MPS_SPP } & $\mathrm{F}(\mathrm{N}=467)$ & 63.40 & 11.35 & -2.71 & .01 & 0.10 \\
\hline & $\mathrm{M}(\mathrm{N}=147)$ & 60.99 & 11.36 & & & \\
\hline \multirow[t]{2}{*}{ BDI } & $\mathrm{F}(\mathrm{N}=467)$ & 10.63 & 8.48 & -4.45 & .001 & 0.18 \\
\hline & $M(N=147)$ & 7.40 & 7.60 & & & \\
\hline \multirow[t]{2}{*}{ PWB-AUT } & $\mathrm{F}(\mathrm{N}=467)$ & 31.70 & 6.23 & -2.95 & .01 & 0.12 \\
\hline & $\mathrm{M}(\mathrm{N}=147)$ & 33.42 & 5.66 & & & \\
\hline \multirow[t]{2}{*}{ PWB-PRO } & $\mathrm{F}(\mathrm{N}=467)$ & 29.48 & 4.45 & -3.38 & .001 & 0.14 \\
\hline & $\mathrm{M}(\mathrm{N}=147)$ & 27.96 & 5.05 & & & \\
\hline
\end{tabular}

Note: NPI-16=Narcissistic traits, MPS-SPP=Socially-Prescribed Perfectionism, BDI - Beck Depression Inventory, PWB-AUT = Psychological Well-Being - Autonomy, PWB-PRO =Psychological Well-Being Positive Relations with Others

Our results indicate that on the entire sample, female participants indicated significantly lower levels of narcissism $(\mathrm{Z}=-3.31, p<.001)$, but significantly higher level of socially prescribed perfectionism $(\mathrm{Z}=-2.71, p<.01)$, significantly higher levels of depressive symptoms $(\mathrm{Z}=-4.45, p<.001)$, significantly lower levels of autonomy $(\mathrm{Z}=-2.95, p<.01)$ and significantly higher levels of positive relations with others $(\mathrm{Z}=-3.38, p<.001)$. In all cases, the effect-sizes of the differences between female and male participants were small.

Next, we conducted a nonparametric t-test to investigate gender differences within age groups. Significant results are presented in Table 4a (millennials) and Table $4 b$ (participants older than 35 years of age). 
EXPLORING AGE AND GENDER DIFFERENCES IN NARCISSISM AND PERFECTIONISM AND THEIR MENTAL-HEALTH CORRELATES

Table 4a. Significant gender differences in narcissism, socially prescribed perfectionism, depressive symptoms, personal growth and positive relations with others in millennials

\begin{tabular}{|c|c|c|c|c|c|c|}
\hline SCALES & Group & Mean & SD & $\mathbf{Z}$ & $p$ & $r$ \\
\hline \multirow[t]{2}{*}{ NPI-16 } & $\mathrm{F}(\mathrm{N}=373)$ & 7.72 & 5.21 & -2.56 & .01 & 0.12 \\
\hline & $\mathrm{M}(\mathrm{N}=94)$ & 9.35 & 4.42 & & & \\
\hline \multirow[t]{2}{*}{ MPS_SPP } & $\mathrm{F}(\mathrm{N}=373)$ & 63.47 & 11.03 & -2.65 & .01 & .012 \\
\hline & $\mathrm{M}(\mathrm{N}=94)$ & 60.37 & 10.67 & & & \\
\hline \multirow[t]{2}{*}{ BDI } & $\mathrm{F}(\mathrm{N}=373)$ & 11.13 & 8.50 & -2.89 & .01 & 0.13 \\
\hline & $\mathrm{M}(\mathrm{N}=94)$ & 8.66 & 8.41 & & & \\
\hline \multirow[t]{2}{*}{ PWB-PG } & $\mathrm{F}(\mathrm{N}=373)$ & 45.96 & 6.02 & -2.41 & .01 & 0.11 \\
\hline & $\mathrm{M}(\mathrm{N}=94)$ & 43.81 & 7.71 & & & \\
\hline \multirow[t]{2}{*}{ PWB-PRO } & $\mathrm{F}(\mathrm{N}=373)$ & 29.48 & 4.37 & -3.67 & .001 & 0.17 \\
\hline & $\mathrm{M}(\mathrm{N}=94)$ & 27.35 & 5.41 & & & \\
\hline
\end{tabular}

Note: NPI-16=Narcissistic traits, MPS-SPP=Socially-Prescribed Perfectionism, BDI - Beck Depression Inventory, $P W B-A U T=$ Psychological Well-Being - Autonomy, $P W B-P G=P e r s o n a l$ Growth, $P W B-P R O=$ Psychological Well-Being - Positive Relations with Others

Table 4b. Significant gender differences in depressive symptoms and loneliness in participants older than 35 years of age

\begin{tabular}{|c|c|c|c|c|c|c|}
\hline SCALES & Group & Mean & SD & $\mathbf{Z}$ & $p$ & $r$ \\
\hline \multirow[t]{2}{*}{ BDI } & $\mathrm{F}(\mathrm{N}=94)$ & 8.60 & 8.16 & -2.31 & .02 & 0.19 \\
\hline & $\mathrm{M}(\mathrm{N}=55)$ & 5.25 & 5.39 & & & \\
\hline \multirow[t]{2}{*}{ UCLA } & $\mathrm{F}(\mathrm{N}=94)$ & 53.44 & 4.00 & -2.31 & .02 & 0.19 \\
\hline & $\mathrm{M}(\mathrm{N}=55)$ & 51.61 & 6.16 & & & \\
\hline
\end{tabular}

Note: BDI - Beck Depression Inventory, UCLA- Loneliness scale

As presented in Tables $4 \mathrm{a}$ and $4 \mathrm{~b}$, split on the two investigated agegroups (millennials and participants over 35 years of age), our results indicate that in the case of millennials, there are significant gender differences in the following variables: male participants report significantly higher levels of narcissistic traits than female participants $(\mathrm{Z}=-2.56, p<.01)$. Nevertheless, female millennials attain significantly higher levels of socially prescribed perfectionism $(\mathrm{Z}=-2.65, p<.01)$, depressive symptoms $(\mathrm{Z}=-2.89, p<.01)$, personal growth $(\mathrm{Z}=-2.41$, $p<.01)$, and positive relations with others $(\mathrm{Z}=-3.67, p<.01)$. In all these differences effect-sizes were rather small, ranging from 0.11 to 0.17 . 
Regarding participants older than 35 years of age, our investigation found significant differences in only two variables: depressive symptoms and loneliness. More specifically, female participants in the older age-groups reported significantly higher levels of depressive symptoms $(Z=-2.31, p<.02)$ and loneliness $(\mathrm{Z}=-2.31, p<.01)$ than male participants. In this situation too, the effect sizes were small (0.19).

Finally, we investigated association patterns between narcissistic traits, multidimensional perfectionism, depressive symptoms, happiness, loneliness and psychological well-being within age and category groups. Results are presented in Tables 5a,b and 6a,b.

First, we will present the correlation matrixes for the assessed variables for women in both age groups in Tables $5 \mathrm{a}$ and $5 \mathrm{~b}$.

Table 5a. Significant correlations in millennial females between narcissistic traits, multidimensional perfectionism, depressive symptoms, happiness, loneliness and psychological well-being within age and category groups

\begin{tabular}{|c|c|c|c|c|c|c|c|c|}
\hline \multirow{14}{*}{$\begin{array}{l}\text { MILLENNIAL } \\
\text { WOMEN }\end{array}$} & & NPI & MPS SOP & MPS OOP & MPS SPP & BDI & UCLA & OXFORD \\
\hline & NPI & 1 & & & & & & \\
\hline & MPS-SOP & $.15^{* *}$ & 1 & & & & & \\
\hline & MPS-00P & NS & $.54^{* *}$ & 1 & & & & \\
\hline & MPS-SPP & $.12^{*}$ & $.64^{* *}$ & $.46^{* *}$ & 1 & & & \\
\hline & BDI & NS & $.12^{*}$ & NS & $.34^{* *}$ & 1 & & \\
\hline & UCLA & $-.26^{*}$ & NS & $.19^{* *}$ & $.16^{* *}$ & $.37^{* *}$ & 1 & \\
\hline & OXFORD & $.26^{* *}$ & $.14^{* *}$ & NS & NS & $-.28^{* *}$ & $-.48^{* *}$ & 1 \\
\hline & PWB-AUT & NS & NS & NS & NS & $-.32^{* *}$ & NS & $.25^{* *}$ \\
\hline & PWB-EM & $.11^{*}$ & $.18^{* *}$ & NS & NS & $-.56^{* *}$ & $-.23^{* *}$ & $.36^{* *}$ \\
\hline & PWB-PG & NS & NS & NS & NS & $-.34^{* *}$ & NS & $.32^{* *}$ \\
\hline & PWB-PRO & NS & NS & NS & NS & $-.26^{* *}$ & $-.19^{* *}$ & $.36^{* *}$ \\
\hline & PWB-PL & $.14^{* *}$ & $.14^{* *}$ & NS & NS & $-.53^{* *}$ & $-.30^{* *}$ & $.36^{* *}$ \\
\hline & PWB-SA & NS & NS & NS & NS & $-.55^{* *}$ & $-.27 * *$ & $.36^{* *}$ \\
\hline
\end{tabular}

Note: NPI-16=Narcissistic traits, MPS-SOP=Multidimensional Perfectionism-Self-Oriented-Perfectionism, MPS-OOP=Multidimensional Perfectionism-Other-Oriented-Perfectionism, MPS-SPP=Socially-Prescribed Perfectionism, BDI - Beck Depression Inventory, UCLA-Loneliness scale, Oxford = Happiness Scale, $P W B-A U T=$ Psychological Well-Being - Autonomy, $P W B-E M=P$ sychological Well-Being - Environmental Mastery, $P W B-P G=$ Psychological Well-Being - Personal Growth, $P W B-P G=$ Psychological Well-Being Positive Relations with Others, $P W B-P L=$ Psychological Well-Being - Purpose in Life, $P W B-S A=$ Psychological Well-Being - Self-Acceptance

${ }^{*} \mathrm{p}<.05 ;{ }^{* *} \mathrm{p}<.01$ 
EXPLORING AGE AND GENDER DIFFERENCES IN NARCISSISM AND PERFECTIONISM AND THEIR MENTAL-HEALTH CORRELATES

Table 5b. Significant correlations in female participants above 35 years of age between narcissistic traits, multidimensional perfectionism, depressive symptoms, happiness, loneliness and psychological well-being within age and category groups

\begin{tabular}{|c|c|c|c|c|c|c|c|c|}
\hline \multirow{14}{*}{$\begin{array}{l}\text { WOMEN } \\
\text { OVER } 35\end{array}$} & & NPI & MPS SOP & MPS OOP & MPS SPP & BDI & UCLA & OXFORD \\
\hline & NPI & 1 & & & & & & \\
\hline & MPS-SOP & NS & 1 & & & & & \\
\hline & MPS-00P & NS & $.52^{* *}$ & 1 & & & & \\
\hline & MPS-SPP & NS & $.66^{* *}$ & $.52^{* *}$ & 1 & & & \\
\hline & BDI & NS & NS & $.22^{*}$ & $.32^{* *}$ & 1 & & \\
\hline & UCLA & NS & $.31^{*}$ & $.30^{* *}$ & $.36^{* *}$ & NS & 1 & \\
\hline & OXFORD & NS & NS & $.24^{*}$ & NS & $-.21^{*}$ & NS & 1 \\
\hline & PWB-AUT & NS & NS & NS & NS & $-.21^{*}$ & NS & $.20^{*}$ \\
\hline & PWB-EM & NS & NS & NS & NS & $-.26^{*}$ & NS & $.28^{* *}$ \\
\hline & PWB-PG & NS & NS & NS & NS & $-.54^{* *}$ & $-.21^{*}$ & $.23^{*}$ \\
\hline & PWB-PRO & NS & NS & NS & NS & $-.40^{* *}$ & $-.28^{* *}$ & NS \\
\hline & PWB-PL & NS & NS & NS & NS & $-.44^{* *}$ & NS & $.30^{* *}$ \\
\hline & PWB-SA & NS & NS & NS & NS & $-.57^{* *}$ & NS & $.35^{*}$ \\
\hline
\end{tabular}

Note: NPI-16=Narcissistic traits, MPS-SOP=Multidimensional Perfectionism-Self-Oriented-Perfectionism, MPS-OOP=Multidimensional Perfectionism-Other-Oriented-Perfectionism, MPS-SPP=Socially-Prescribed Perfectionism, BDI - Beck Depression Inventory, UCLA-Loneliness scale, Oxford = Happiness Scale, $P W B$-AUT = Psychological Well-Being - Autonomy, $P W B$-EM =Psychological Well-Being - Environmental Mastery, $P W B-P G=$ Psychological Well-Being - Personal Growth, $P W B-P G=$ Psychological Well-Being Positive Relations with Others, $P W B-P L=$ Psychological Well-Being - Purpose in Life, $P W B-S A=$ Psychological Well-Being - Self-Acceptance

${ }^{*} \mathrm{p}<.05 ;{ }^{* *} \mathrm{p}<.01$

As seen in Table 5a, in the case of millennial women (under age of 35), there was a weak positive correlation between narcissism and self-oriented perfectionism $(\mathrm{r}=.15, p<.01)$, socially prescribed perfectionism $(\mathrm{r}=.12, p<.05)$, happiness $(\mathrm{r}=.26, p<.01)$, environmental mastery $(\mathrm{r}=.11, p<.01)$, and purpose in life $(\mathrm{r}=.14, p<.01)$, and a negative correlation between narcissism and loneliness $(\mathrm{r}=-.26, p<.05)$. Self-oriented perfectionism was positively correlated with both depression $(\mathrm{r}=.12, p<.05)$ and happiness $(\mathrm{r}=.14, p<.01)$, as well as emotional mastery $(\mathrm{r}=.18, p<.01)$, and purpose in life $(\mathrm{r}=.14, p<.01)$. Other oriented perfectionism was significantly correlated only with: loneliness $(\mathrm{r}=.19, p<.01)$, and socially prescribed perfectionism was narcissism $(\mathrm{r}=.12, p<.05)$, depressive symptoms $(\mathrm{r}=.34, p<.01)$, and loneliness $(\mathrm{r}=.16, p<.01)$. Loneliness was positively correlated with other oriented perfectionism $(\mathrm{r}=.19, \mathrm{p}<.01)$, socially prescribed perfectionism $(\mathrm{r}=.16, \mathrm{p}<.01)$, and depressive symptomatology 
( $\mathrm{r}=.37, p<.01$ ), and negatively correlated with subjective well-being (happiness) $(\mathrm{r}=-.48, p<.01)$, environmental mastery $(\mathrm{r}=-.23, p<.01)$, positive relations with others $(\mathrm{r}=-.19, \mathrm{p}<.01)$, purpose in life $(\mathrm{r}=-.30, p<.01)$, and self-acceptance $(\mathrm{r}=-.27$, $p<.01$ ). Depression was positively correlated with two scales of MPS (self-oriented perfectionism, $\mathrm{r}=.12, p<.05$; SPP, $\mathrm{r}=.34, p<.01$ ), and negatively correlated with subjective well-being $(\mathrm{r}=-.28, p<.01)$. In this age and gender groups, depressive symptoms also presented significant negative correlations with all the components of psychological well-being: autonomy $(\mathrm{r}=-.32, p<.01)$, environmental mastery $(\mathrm{r}=-.56, p<.01)$, personal growth $(\mathrm{r}=-.34, p<.01)$, positive relations with others $(\mathrm{r}=-.26, p<.01)$, purpose in life $(\mathrm{r}=.-.53, p<.01)$, and self-acceptance $(\mathrm{r}=-.55$, $p<.01)$.

In the case of women over 35 years of age, there was no correlation whatsoever between narcissism and the other assessed variables. As seen in Table $5 \mathrm{~b}$, in the case of women in this age group, self-oriented perfectionism was positively correlated only with loneliness $(\mathrm{r}=.31, p<.05)$, while other oriented perfectionism was also positively correlated with loneliness $(\mathrm{r}=.30$, $p<.01)$, depression $(\mathrm{r}=.22, p<.05)$, and also positively correlated with subjective well-being $(\mathrm{r}=.24, p<.05)$. Furthermore, in this category of participants, socially prescribed perfectionism was positively correlated with loneliness $(\mathrm{r}=.36$, $p<.01)$ and depression $(\mathrm{r}=.32, p<.01)$, while depression was negatively correlated with subjective well-being $(\mathrm{r}=-.21, p<.05)$, autonomy $(\mathrm{r}=-.21, p<.05)$, environmental mastery $(\mathrm{r}=-.26, p<.05)$, personal growth $(\mathrm{r}=-.54, p<.01)$, positive relations with others $(\mathrm{r}=-.40, p<.01)$, purpose in life $(\mathrm{r}=0.44, p<.01)$, and self-acceptance ( $r=.57, p<.01)$. Regarding the relationship between loneliness and the components of psychological well-being, our results indicate that loneliness is negatively correlated with personal growth $(\mathrm{r}=-.21, p<.01)$, and positive relations with others $(\mathrm{r}=-.28, p<.01)$, while subjective well-being is positively associated with autonomy $(\mathrm{r}=.20, p<.05)$, environmental mastery $(\mathrm{r}=.28, p<.01)$, personal growth $(\mathrm{r}=.23, p<.01)$, purpose in life $(\mathrm{r}=.30, p<.01)$, and self-acceptance $(\mathrm{r}=.35, p<.01)$.

Next, we will present the correlation matrixes for the assessed variables for male participants in both age groups in Tables $6 \mathrm{a}$ and $6 \mathrm{~b}$.

As seen in Table $6 \mathrm{a}$, in the case of millennial males, there was a positive correlation between narcissism and subjective well-being ( $\mathrm{r}=.21, p<.05)$, and environmental mastery $(\mathrm{r}=.20, p<.05)$. Self-oriented perfectionism was positively associated with autonomy $(\mathrm{r}=.24, p<.01)$, and purpose in life $(\mathrm{r}=.26, p<.05)$. Other oriented perfectionism was positively associated only with autonomy $(\mathrm{r}=.22, p<.01)$. Socially prescribed perfectionism was positively correlated with depression $(\mathrm{r}=.32, p<.01)$ and loneliness $(\mathrm{r}=.22, p<.05)$, results similar to those of women under 35 years old. Depressive symptoms presented a significant 
EXPLORING AGE AND GENDER DIFFERENCES IN NARCISSISM AND PERFECTIONISM AND THEIR MENTAL-HEALTH CORRELATES

negative association pattern with: autonomy $(\mathrm{r}=.-37, p<.01)$, environmental mastery $(\mathrm{r}=-.74, p<.01)$, personal growth $(\mathrm{r}=-.50, p<.01)$, positive relations with others ( $\mathrm{r}=-.51, p<.01)$, purpose in life $(\mathrm{r}=.-64, p<.01)$, and self-acceptance $(\mathrm{r}=-.62$, $p<.01)$. Finally, similar to women under 35 years old, subjective well-being was negatively correlated with depression $(\mathrm{r}=-.43, p<.01)$ and loneliness $(\mathrm{r}=-.36$, $p<.01)$, and positively with: autonomy $(\mathrm{r}=.37, p<.01)$, environmental mastery $(.48, p<.01)$, personal growth $(\mathrm{r}=45, p<.01)$, positive relations with others $(\mathrm{r}=.47, p<.01)$, purpose in life $(\mathrm{r}=.51, p<.01)$, and self-acceptance $(\mathrm{r}=.43, \mathrm{p}<.01)$.

Table 6a. Significant correlations in millennial males between narcissistic traits, multidimensional perfectionism, depressive symptoms, happiness, loneliness and psychological well-being within age and category groups

\begin{tabular}{|c|c|c|c|c|c|c|c|c|}
\hline \multirow{14}{*}{$\begin{array}{l}\text { MILLENNIAL } \\
\text { MEN }\end{array}$} & & NPI & MPS SOP & MPS OOP & MPS SPP & BDI & UCLA & OXFORD \\
\hline & NPI & 1 & & & & & & \\
\hline & MPS-SOP & NS & 1 & & & & & \\
\hline & MPS-00P & NS & $.46^{* *}$ & 1 & & & & \\
\hline & MPS-SPP & NS & $.55^{* *}$ & $.482^{* *}$ & 1 & & & \\
\hline & BDI & NS & NS & NS & $.32^{* *}$ & 1 & & \\
\hline & UCLA & NS & NS & NS & $.22^{*}$ & NS & 1 & \\
\hline & OXFORD & $.21^{*}$ & NS & NS & NS & $-.43^{* *}$ & $-.36^{* *}$ & 1 \\
\hline & PWB-AUT & NS & $.24^{* *}$ & $.22^{* *}$ & NS & $-.37^{* *}$ & NS & $.37^{* *}$ \\
\hline & PWB-EM & $.20 *$ & NS & NS & NS & $-.74 * *$ & NS & $.48^{* *}$ \\
\hline & PWB-PG & NS & NS & NS & NS & $-.50^{* *}$ & NS & $.45^{* *}$ \\
\hline & PWB-PRO & NS & NS & NS & NS & $-.51^{* *}$ & NS & $.47^{* *}$ \\
\hline & PWB-PL & NS & $.26^{*}$ & NS & NS & $-.64 * *$ & NS & $.51^{* *}$ \\
\hline & PWB-SA & NS & NS & NS & NS & $-.62^{* *}$ & NS & $.43^{* *}$ \\
\hline
\end{tabular}

Note: NPI-16=Narcissistic traits, MPS-SOP=Multidimensional Perfectionism-Self-Oriented-Perfectionism, MPS-OOP=Multidimensional Perfectionism-Other-Oriented-Perfectionism, MPS-SPP=Socially-Prescribed Perfectionism, BDI - Beck Depression Inventory, UCLA-Loneliness scale, Oxford = Happiness Scale, $P W B$-AUT = Psychological Well-Being - Autonomy, $P W B-E M=$ Psychological Well-Being - Environmental Mastery, $P W B-P G=$ Psychological Well-Being - Personal Growth, $P W B-P G=$ Psychological Well-Being Positive Relations with Others, $P W B-P L=$ Psychological Well-Being - Purpose in Life, $P W B-S A=$ Psychological Well-Being - Self-Acceptance ${ }^{*} \mathrm{p}<.05 ;{ }^{* *} \mathrm{p}<.01$ 
ÉVA KÁLLAY, ALEXANDRA REBECA MIHOC

Table 6b. Significant correlations in male participants above 35 years of age between narcissistic traits, multidimensional perfectionism, depressive symptoms, happiness, loneliness and psychological well-being within age and category groups

\begin{tabular}{|c|c|c|c|c|c|c|c|c|}
\hline \multirow{14}{*}{$\begin{array}{c}\text { MEN } \\
\text { OVER } 35\end{array}$} & & NPI & MPS SOP & MPS OOP & MPS SPP & BDI & UCLA & OXFORD \\
\hline & NPI & 1 & & & & & & \\
\hline & MPS-SOP & $.29 *$ & 1 & & & & & \\
\hline & MPS-00P & NS & $.71^{* *}$ & 1 & & & & \\
\hline & MPS-SPP & NS & $.77^{* *}$ & $.77^{* *}$ & 1 & & & \\
\hline & BDI & $.42^{* *}$ & $.33^{*}$ & $.29^{*}$ & $.31^{*}$ & 1 & & \\
\hline & UCLA & NS & NS & NS & NS & $.38^{* *}$ & 1 & \\
\hline & OXFORD & $.35^{*}$ & $.51^{* *}$ & $.44^{* *}$ & $.49 * *$ & NS & NS & 1 \\
\hline & PWB-AUT & NS & $.42^{* *}$ & $.40^{* *}$ & NS & NS & NS & $.52^{* *}$ \\
\hline & PWB-EM & NS & $.40^{* *}$ & $.39^{* *}$ & NS & NS & NS & $.31^{* *}$ \\
\hline & PWB-PG & NS & $.40^{* *}$ & $.36^{* *}$ & $.27^{*}$ & NS & NS & $.43^{* *}$ \\
\hline & PWB-PRO & NS & NS & NS & NS & NS & NS & $.36^{* *}$ \\
\hline & PWB-PL & NS & $.44^{* *}$ & $.36^{* *}$ & NS & NS & NS & $.36^{* *}$ \\
\hline & PWB-SA & NS & $.30^{*}$ & NS & NS & NS & NS & $.34^{*}$ \\
\hline
\end{tabular}

Note: NPI-16=Narcissistic traits, MPS-SOP=Multidimensional Perfectionism-Self-Oriented-Perfectionism, MPS-OOP=Multidimensional Perfectionism-Other-Oriented-Perfectionism, MPS-SPP=Socially-Prescribed Perfectionism, BDI - Beck Depression Inventory, UCLA-Loneliness scale, Oxford = Happiness Scale, $P W B-A U T=P$ sychological Well-Being - Autonomy, $P W B-E M=P$ sychological Well-Being - Environmental Mastery, $P W B-P G=$ Psychological Well-Being - Personal Growth, $P W B-P G=$ Psychological Well-Being Positive Relations with Others, $P W B-P L=$ Psychological Well-Being - Purpose in Life, $P W B-S A=$ Psychological Well-Being - Self-Acceptance

${ }^{*} \mathrm{p}<.05 ;{ }^{* *} \mathrm{p}<.01$

In the case of male participants over 35 years of age, as we see in Table $6 \mathrm{~b}$, there was a positive correlation between narcissism and self-oriented perfectionism $(\mathrm{r}=.29, p<.05)$, depression $(\mathrm{r}=.42, p<.01)$ and subjective wellbeing $(\mathrm{r}=.35, p<.05)$. Self-oriented perfectionism presented significant positive correlations with: depression ( $\mathrm{r}=.33, p<.05)$, subjective well-being $(\mathrm{r}=.51, p<.01)$, autonomy $(\mathrm{r}=.42, p<.01)$, environmental mastery $(\mathrm{r}=.40, p<.01)$, personal growth $(\mathrm{r}=.40, \mathrm{p}<.01)$, purpose in life $(\mathrm{r}=.44, p<.01)$, and self-acceptance $(\mathrm{r}=.30$, $p<.01$ ). Within this age group, other oriented perfectionism was found to be significantly correlated with:depressive symptoms $(\mathrm{r}=.29, p<.05)$, subjective well-being ( $\mathrm{r}=.44, p<.01)$, autonomy $(\mathrm{r}=.40, p<.01)$, environmental mastery $(\mathrm{r}=.39, p<.01)$, personal growth $(\mathrm{r}=.36, p<.01)$, purpose in life $(\mathrm{r}=.36, p<.01)$, and socially prescribed perfectionism was significantly associated with depressive symptoms $(\mathrm{r}=.31, p<.05)$, subjective well-being $(\mathrm{r}=.49, p<.01)$, and personal growth $(\mathrm{r}=.27, p<.05)$. Loneliness was positively correlated with depression $(\mathrm{r}=.38, p<.01)$. As in all previous age and gender groups, in male participants over 35 years if age subjective well-being presented similar correlational patterns with 
all the components of psychological well-being, namely: autonomy $(\mathrm{r}=.52, p<.01)$, environmental mastery $(\mathrm{r}=.31, p<.01)$, personal growth $(\mathrm{r}=.43, p<.01)$, positive relations with others $(\mathrm{r}=.36, p<.01)$, purpose in life $(\mathrm{r}=.36, p<.01)$, and selfacceptance $(\mathrm{r}=.34, p<.01)$.

\section{Conclusions and Discussions}

Scientific literature has rigorously documented alarming tendencies regarding significant increases in mental-health problems (depressive symptoms, anxiety, loneliness) (Collins, Patel, Joestl, March, Insel, \& Daar, 2011; Erzen \& Çikrikçi, 2018; Hawkley \& Cacioppo, 2010; Perissinotto, Stijacic Cenzer, \& Covinsky, 2012; Prina, Victor, \& Bowling, 2012; WHO, 2017), as well as maladaptive forms of personality characteristics (narcissism, perfectionism) (Curran \& Hill, 2017; Twenge, 2006; Twenge \& Campbell, 2008; Twenge \& Campbell, 2009). The extant research indicates mixed results. Some investigations report a positive association between pathological narcissism and depression (Kealy, Laverdière, \& Pincus, 2020;), while other studies indicate that narcissistic traits might protect the person from the development of depression (e.g., Veselka, Schermer, \& Vernon, 2012). Furthermore, literature also indicates that perfectionism is a central feature of narcissism (Ronningstam, 2010, 2011), and is a strong predictor of depression (Hewitt, Flett, \& Ediger, 1996). Unfortunately, based on demographic variables, literature offers mixt results regarding the groups of populations that are highest at risk for developing maladaptive forms especially in relation to narcissism and perfectionism. Some studies indicate that younger generations present higher levels of narcissism, with narcissistic traits decreasing over time (Foster, Campbell, \& Twenge, 2003, Roberts, Edmonds, \& Grijalva, 2010), while other studies sustain that there is no direct evidence for such claims (Arnett, 2013; Trzesniewski, Donnellan, \& Robins, 2008a; Trzesniewski, Donnellan, \& Robins, 2008b; Twenge, Campbell, \& Freeman, 2012; Twenge, Campbell, Hoffman, \& Lance, 2010). Furthermore, besides systematically recorded differences in depression between men and women, literature has no stable results indicating similar gender-related differences in narcissism and perfectionism (Sherry et al., 2014).

Since the number of studies investigating these relationships in the Romanian population are scarce, our present study intended to investigate: (1) possible age and gender differences in narcissism, perfectionism and mentalhealth indicators (depression, happiness, loneliness and psychological wellbeing) in a sample of healthy participants, and specific association patterns between narcissistic traits, perfectionism and mental health indicators (depressive symptoms, loneliness, happiness and psychological well-being) within each group of participants (age - millennials and above 35 years of age, and gender). 
Our results indicate that in our sample the millennials reported significantly lower levels of narcissistic traits than the older generation, a rather surprising finding, especially if we consider that in the majority of the studies conducted in the Anglo-Saxon societies this tendency seems to be inclined in the opposite direction. The situation is the same in the case of multidimensional perfectionism, namely, in our sample, the older generation (those above 35 years of age) presents significantly higher levels of self- and other oriented perfectionism. These differences may be attributable to cultural specificities of our sample, but further investigations are required to find the more specific underlying motives of these controversial results. Moreover, the older generations indicated significantly lower levels of depressive symptoms and significantly higher levels of autonomy, environmental mastery, purpose if life, and self-acceptance. Corroborated with the differences in depression and psychological well-being, these results may indicate to some degree that in the case of participants older than 35 years of age, narcissism and self-and other-oriented perfectionism may play a protective role in face of depression (Foster, Campbell, \& Twenge, 2003; Roberts, Edmonds, \& Grijalva, 2010).

Regarding gender differences, for the entire sample, our results indicate that our male participants reported significantly higher levels of narcissism and autonomy, while female participants reported significantly higher levels of socially prescribed perfectionism, depressive symptoms, and positive relations with others. Split on gender and age groups (millennial females and males, and above 35 years of age females and males), results become a bit more specific. Within the millennials' age group, male participants report significantly higher levels of narcissistic traits, while female participants significantly higher levels of socially prescribed perfectionism, depressive symptoms, personal growth, and positive relations with others. This gender difference is no longer maintained in the group of older participants, where we found only two significant differences: female participants indicated significantly higher levels of depressive symptoms and loneliness than male participants. Thus, this far we may conclude that in our sample, the gender differences regarding narcissism and perfectionism are valid only in the case of millennials. What is also very important to keep in mind is that depression is significantly higher in the group of female participants in both age groups.

Our second objective was to investigate correlation patterns in both age and gender groups. Results indicate that in the group of millennial women narcissistic traits are positively correlated with self-oriented and sociallyprescribed perfectionism and subjective well-being, and negatively with loneliness, environmental mastery and purpose in life. These results are somewhat in line with the results obtained in the literature, which indicate that there is a significant association between narcissistic traits and perfectionism, and dysfunctional emotions (in this case loneliness). In the case of millennial 
male participants, the only associations we found positive correlations only between narcissism and subjective well-being and environmental mastery, which is also in line with the research suggesting these kinds of relationships (Egan, Chan, \& Shorter, 2014; Jonason, Baughman, Carter, \& Parker, 2015; Sedikides, Rudich, Gregg, Kumashiro, \& Rusbult, 2004). Within the group of participants with age above 35 years, we found no significant associations between narcissism and the assessed variables in the case of female participants. Regarding males, within this age group narcissism presented quite surprisingly significant positive correlation with self-oriented perfectionism, depressive symptomatology and subjective well-being.

Based on our results, we may conclude that regarding narcissism and perfectionism the most vulnerable population seems to be that of millennial females, who present significantly higher levels of these variables both compared to males and their older counterparts. By the same token, in their group these variables present maladaptive association patterns with the assessed mental health indicators.

\section{Limitations}

Besides the results presented in this pilot study, our investigation has several limitations of which we are fully aware and take responsibility for. First of all, our study is a cross-sectional research and can only hint towards possible vulnerabilities, without having the possibility to drive rock-solid conclusions regarding vulnerabilities and subjacent mechanisms. Also, our study involved a relatively low number of participants, within a specific geographic area, and the gender distribution was also quite unequal in the two age-groups. Next, since we used for brevity's sake the NPI-16, we could not refine our results regarding the different types of narcissism (grandiose and covert), which might have significantly improved the informative value of the conclusions of our investigation. Thirdly, in our study, the number of millennials was larger than that of persons older than 35 years of age. Future studies should also concentrate on similar representations in number of age-groups. We propose that this aspect be also taken into consideration by future investigations. The results of our investigation may have informative value for the continuation of more thorough investigations within this area of interest. Furthermore, we also consider that our results may be useful for further studies. 
ÉVA KÁLLAY, ALEXANDRA REBECA MIHOC

\section{REFERENCES}

American Psychiatric Association. (2013). Diagnostic and statistical manual of mental disorders ( $5^{\text {th }}$ Ed.). Washington, DC: Author.

Ames, D. R., Rose, P., \& Anderson, C. P. (2006). The NPI-16 as a short measure of narcissism. Journal of Research in Personality, 40(4), 440-450.

Amiri, S., Sepehrian Azar, F., \& Ghasemi Navab, A. (2017). Investigate psychological wellbeing, happiness and emotion regulation in dark triad personality tendencies. Journal of Psychological Studies, 13(2), 25-42.

Anderson, C. A., Miller, R. S., Riger, A. L., Dill, J. C., \& Sedikides, C. (1994). Behavioral and characterological attributional styles as predictors of depression and loneliness: Review, refinement, and test. Journal of Personality and Social Psychology, 66(3), 549.

Andrews, F. M., \& Robinson, J. P. (1991). Measures of subjective well-being. Measures of Personality and Social Psychological Attitudes, 1, 61-114.

Arnett, J. J. (2013). The evidence for generation we and against generation me. Emerging Adulthood, 1(1), 5-10.

Ashby, J. S., Dickinson, W. L., Gnilka, P. B., \& Noble, C. L. (2011). Hope as a mediator and moderator of multidimensional perfectionism and depression in middle school students. Journal of Counseling \& Development, 89(2), 131-139.

Banyard, V. L., Kendall-Tackett, K. A., \& Edwards, V. J. (2009). Trauma and Physical Health: Understanding the effects of extreme stress and of psychological harm (1 $1^{\text {st }}$ Ed.). Routledge.

Bauman, Z. (2000). Liquid Modernity. Cambridge: Polity.

Bauman, Z. (2007). Liquid times: Living in an age of uncertainty. Cambridge: Polity.

Beck, A. T., Rush, A. J., Shaw, B. F., Emery, G. (1979). Cognitive therapy of depression. New York, NY: Guilford Press.

Beck, A. T., Freeman, A., Davis, D. D., Pretzer, J., Fleming, B., \& Beck, J. S. (2004). Cognitive therapy of personality disorders. New York. NY: Guilford.

Besser, A., Flett, G. L., \& Hewitt, P. L. (2004). Perfectionism, cognition, and affect in response to performance failure vs. success. Journal of Rational-Emotive and Cognitive-Behavior Therapy, 22(4), 297-324.

Besser, A., Flett, G. L., Hewitt, P. L., \& Guez, J. (2008). Perfectionism, and cognitions, affect, self-esteem, and physiological reactions in a performance situation. Journal of Rational-Emotive \& Cognitive-Behavior Therapy, 26(3), 206-228.

Bor, W., Dean, A. J., Najman, J., \& Hayatbakhsh, R. (2014). Are child and adolescent mental health problems increasing in the 21st century? A systematic review. Australian \& New Zealand Journal of Psychiatry, 48(7), 606-616.

Boyle, P. A., Barnes, L. L., Buchman, A. S., \& Bennett, D. A. (2009). Purpose in life is associated with mortality among community-dwelling older persons. Psychosomatic Medicine, 71(5), 574-579. doi:10.1097/PSY.0b013e3181a5a7c0 
EXPLORING AGE AND GENDER DIFFERENCES IN NARCISSISM AND PERFECTIONISM AND THEIR MENTAL-HEALTH CORRELATES

Carter, G. L., \& Douglass, M. D. (2018). The aging narcissus: just a myth? Narcissism moderates the age-loneliness relationship in older age. Frontiers in Psychology, 9, 1254.

Cacioppo, J. T., \& Patrick, W. (2008). Loneliness. Human nature and the need for social connection. W.W. Norton \& Co.

Caligor, E., Levy, K. N., \& Yeomans, F. E. (2015). Narcissistic personality disorder: Diagnostic and clinical challenges. American Journal of Psychiatry, 172(5), 415-422.

Chang, E. C., \& Farrehi, A. S. (2001). Optimism/pessimism and information-processing styles: can their influences be distinguished in predicting psychological adjustment? Personality and Individual Differences, 31(4), 555-562.

Chang, E. C. (2006). Perfectionism and dimensions of psychological well-being in a college student sample: A test of a stress-mediation model. Journal of Social and Clinical Psychology, 25(9), 1001-1022.

Chang, E. C., Sanna, L. J., Chang, R., \& Bodem, M. R. (2008). A preliminary look at loneliness as a moderator of the link between perfectionism and depressive and anxious symptoms in college students: Does being lonely make perfectionistic strivings more distressing? Behavior Research and Therapy, 46(7), 877-886.

Collins, P. Y., Patel, V., Joestl, S. S., March, D., Insel, T. R., Daar, A. S., ... \& Walport, M. (2011). Grand challenges in global mental health. Nature, 475(7354), 27-30

Collishaw, S., Gardner, F., Maughan, B., Scott, J., \& Pickles, A. (2012). Do historical changes in parent-child relationships explain increases in youth conduct problems? Journal of Abnormal Child Psychology, 40(1), 119-132.

Cramer, P. (2011). Young adult narcissism: A 20-year longitudinal study of the contribution of parenting styles, preschool precursors of narcissism, and denial. Journal of Research in Personality, 45, 19-28.

Curran, T., \& Hill, A.P. (2017). Perfectionism is increasing over time: A meta-analysis of birth cohort differences from 1989 to 2016. Psychological Bulletin, 145(4), 410429. https://doi.org/10.1037/bul0000138

David, D., \& Dobrean, A. (2012). Beck depression Inventory -(BDI-II). Romanian Psychological Testing Services. Cluj-Napoca.

Diener, E. (1984). Subjective well-being. Psychological Bulletin, 95, 542-575.

Diener, E., Gohm, C. L., Suh, E., \& Oishi, S. (2000). Similarity of the relations between marital status and subjective well-being across cultures. Journal of Cross-cultural Psychology, 31(4), 419-436.

Diener, E., Lucas, R. E., \& Oishi, S. (2002). Subjective well-being: The science of happiness and life satisfaction. In C. R. Snyder \& S. J. Lopez (Eds.), Handbook of positive psychology (p. 463-73). Oxford University Press.

Egan, V., Chan, S., \& Shorter, G. W. (2014). The Dark Triad, happiness and subjective well-being. Personality and Individual Differences, 67, 17-22.

Enns, M. W., \& Cox, B. J. (2005). Perfectionism, stressful life events, and the 1-year outcome of depression. Cognitive Therapy and Research, 29(5), 541-553.

Erzen, E., \& Çikrikçi Ö. (2018). The effect of loneliness on depression: A meta-analysis. International Journal of Social Psychiatry, 64(5), 427-435.

https://doi.org/10.1177/0020764018776349 
Flett, G. L., Sherry, S. B., Hewitt, P. L., \& Nepon, T. (2014). Understanding the narcissistic perfectionists among us: Grandiosity, vulnerability, and the quest for the perfect self. In A. Besser (Ed.), Psychology of emotions, motivations and actions. Handbook of the psychology of narcissism: Diverse perspectives (p. 43-66). Nova Science Publishers.

Flett, G. L., Hewitt, P. L., Blankstein, K. R., Solnik, M., \& Van Brunschot, M. (1996). Perfectionism, social problem-solving ability, and psychological distress. Journal of Rational-Emotive and Cognitive-Behavior Therapy, 14(4), 245-274.

Folkman, S., \& Moskowitz, J. T. (2004). Coping: Pitfalls and promise. Annual Review of Psychology, 55, 745-774.

Foster, J. D., Campbell, W. K., \& Twenge, J. M. (2003). Individual differences in narcissism: Inflated self-views across the lifespan and around the world. Journal of Research in Personality, 37, 469-486

Frost, R. O., Marten, P., Lahart, C., \& Rosenblate, R. (1990). The dimensions of perfectionism. Cognitive therapy and research, 14(5), 449-468.

Fry, P. S., \& Debats, D. L. (2009). Perfectionism and the five-factor personality traits as predictors of mortality in older adults. Journal of Health Psychology, 14(4), 513524.

Fry, R. (2018). Millennials are the largest generation in the US labor force. Pew Research Center, 11.

Garnefski, N., Teerds, J., Kraaij, V., Legerstee, J., \& van Den Kommer, T. (2004). Cognitive emotion regulation strategies and depressive symptoms: Differences between males and females. Personality and Individual Differences, 36(2), 267-276.

Gnilka, P. B., Ashby, J. S., \& Noble, C. M. (2012). Multidimensional perfectionism and anxiety: Differences among individuals with perfectionism and tests of a copingmediation model. Journal of Counseling \& Development, 90(4), 427-436.

Goodman, J., Schlossberg, N. K., \& Anderson, M. L. (2006). Counseling adults in transition: Linking practice with theory. Springer Publishing Co.

Grijalva, E., Newman, D. A., Tay, L., Donnellan, M. B., Harms, P. D., Robins, R. W., \& Yan, T. (2015). Gender differences in narcissism: a meta-analytic review. Psychological Bulletin, 141(2), 261.

Gustavsson, A., Svensson, M., Jacobi, F., Allgulander, C., Alonso, J., Beghi, E., Olesen, J. (2011). Cost of disorders of the brain in Europe 2010. European Neuropsychopharmacology, 21(10), 718-779.

Hawkley, L. C., \& Cacioppo, J. T. (2010). Loneliness matters: A theoretical and empirical review of consequences and mechanisms. Annals of Behavioral Medicine, 40(2), 218-227.

Hewitt, P. L., \& Flett, G. L. (1991). Perfectionism in the self and social contexts: conceptualization, assessment, and association with psychopathology. Journal of Personality and Social Psychology, 60(3), 456.

Hewitt, P. L., \& Flett, G. L. (1993). Dimensions of perfectionism, daily stress, and depression: a test of the specific vulnerability hypothesis. Journal of abnormal psychology, 102(1), 58. 
EXPLORING AGE AND GENDER DIFFERENCES IN NARCISSISM AND PERFECTIONISM AND THEIR MENTAL-HEALTH CORRELATES

Hewitt, P. L., Flett, G. L., \& Weber, C. (1994). Dimensions of perfectionism and suicide ideation. Cognitive Therapy and Research, 18(5), 439-460.

Hewitt, P. L., Flett, G. L., \& Ediger, E. (1996). Perfectionism and depression: longitudinal assessment of a specific vulnerability hypothesis. Journal of Abnormal Psychology, 105(2), 276.

Hewitt, P. L., Flett, G. L., Sherry, S. B., Habke, M., Parkin, M., Lam, R. W., ... \& Stein, M. B. (2003). The interpersonal expression of perfection: Perfectionistic self-presentation and psychological distress. Journal of Personality and Social Psychology, 84(6), 1303.

Hewitt, P. L., \& Flett, G L. (2004). The Multidimensional Perfectionism Scale: Professional manual. Toronto: Multi-Health Systems, Inc.

Hewitt, P. L., Flett, G. L., Mikail, S. F., Kealy, D., \& Zhang, L. C. (2018). Perfectionism in the therapeutic context: The perfectionism social disconnection model. In J. Stoeber (Ed.), The psychology of perfectionism: Theory, research, applications (p. 306329). Routledge: Taylor \& Francis Group.

Hewitt, P. L., Flett, G. L., \& Mikail, S. F. (2017). Perfectionism: A relational approach to conceptualization, assessment, and treatment. New York: The Guilford Press.

Hickman, S. E., Watson, P. J., \& Morris, R. J. (1996). Optimism, pessimism, and the complexity of narcissism. Personality and Individual Differences, 20(4), 521-525.

Hill, R. W., McIntire, K., \& Bacharach, V. R. (1997). Perfectionism and the big five factors. Journal of Social Behavior and Personality, 12(1), 257.

Hill, R. W., Zrull, M. C., \& Turlington, S. (1997). Perfectionism and interpersonal problems. Journal of Personality Assessment, 69(1), 81-103.

Hill, P. L., \& Lapsley, D. K. (2011). Adaptive and maladaptive narcissism in adolescent development. In C. T. Barry, P. K. Kerig, K. K. Stellwagen, \& T. D. Barry (Eds.), Narcissism and Machiavellianism in youth: Implications for the development of adaptive and maladaptive behavior (p. 89-105). American Psychological Association. https://doi.org/10.1037/12352-005

Hill, P. L., \& Turiano, N. A. (2014). Purpose in Life as a Predictor of Mortality Across Adulthood. Psychological Science 25(7), 1482-86.

Hills, P., \& Argyle, M. (2002). The Oxford Happiness Questionnaire: a compact scale for the measurement of psychological well-being. Personality and Individual Differences, 33(7), 1073-1082.

Jonason, P. K., Baughman, H. M., Carter, G. L., \& Parker, P. (2015). Dorian Gray without his portrait: Psychological, social, and physical health costs associated with the Dark Triad. Personality and Individual Differences, 78, 5-13.

Kahneman, D., Diener, E., \& Schwarz, N. (Eds.). (1999). Well-being: Foundations of hedonic psychology. Russell Sage Foundation.

Kállay, É., \& Rus, C. (2014). Psychometric properties of the 44-item version of Ryff's Psychological Well-Being Scale. European Journal of Psychological Assessment, 30(1), 15-21. doi: 10.1027/1015-5759/a000163

Kealy, D., Laverdière, O., \& Pincus, A. L. (2020). Pathological narcissism and symptoms of major depressive disorder among psychiatric outpatients: The mediating role of impaired emotional processing. The Journal of Nervous and Mental Disease, 208(2), 161-164. 
King, L. A., \& Napa, C. K. (1998). What makes a life good? Journal of Personality and Social Psychology, 75(1), 156.

Klerman, G., \& Weissman, M. M. (1988). The changing epidemiology of depression. Clinical Chemistry, 34(5), 807-812.

Klerman, G. L., \& Weissman, M. M. (1989). Increasing rates of depression. Jama, 261(15), 2229-2235.

Kohut, H. (1977). The restoration of the self. New York: International Universities Press.

Lasch, C. (1979). The culture of narcissism. Bulletin of the Menninger Clinic, 44(5), 426.

Markus, H. R., \& Kitayama, S. (1991). Culture and the self: Implications for cognition, emotion, and motivation. Psychological Review, 98(2), 224.

Martin, T. R., Flett, G. L., Hewitt, P. L., Krames, L., \& Szanto, G. (1996). Personality correlates of depression and health symptoms: A test of a self-regulation model. Journal of Research in Personality, 30(2), 264-277.

Martin, R. C., \& Dahlen, E. R. (2005). Cognitive emotion regulation in the prediction of depression, anxiety, stress, and anger. Personality and Individual Differences, 39(7), 1249-1260.

Martin, T. H. (2018). Investing in Millennials. Retrieved on January 10, 2021. https://scholars.unh.edu/cgi/viewcontent.cgi?article=1000\&context=paul_bigdata

McGregor, I., \& Little, B. R. (1998). Personal projects, happiness, and meaning: on doing well and being yourself. Journal of Personality and Social Psychology, 74(2), 494.

Moirangthem, S., \& Panda, S. (2018). Happiness across Age Groups: Findings Based on Three Measures.

Oeppen, J., \& Vaupel, J. W. (2002). Broken limits to life expectancy. Science, 296(5570), 1029-1031.doi: 10.1126/science.1069675

Oishi, S., Kesebir, S., \& Diener, E. (2011). Income inequality and happiness. Psychological Science, 22(9), 1095-1100.

Papageorgiou, K. A., Denovan, A., \& Dagnall, N. (2019). The positive effect of narcissism on depressive symptoms through mental toughness: Narcissism may be a dark trait but it does help with seeing the world less grey. European Psychiatry, 55, 74-79.

Patalay, P., \& Fitzsimons, E. (2017). Mental ill-health among children of the new century: trends across childhood with a focus on age 14. London: Centre for Longitudinal Studies.

Patalay, P., \& Gage, S. H. (2019). Changes in millennial adolescent mental health and health-related behaviors over 10 years: a population cohort comparison study. International Journal of Epidemiology, 48(5), 1650-1664.

Paulhus, D. L., \& Williams, K. M. (2002). The dark triad of personality: Narcissism, Machiavellianism, and psychopathy. Journal of Research in Personality, 36(6), 556-563.

Paulsen, J. A., Trzesniewski, K., Syed, M.\& Donnellan, B. (2015). A generational perspective of emerging adulthood: A focus on narcissism. In J. J. Arnett (Ed.) The Oxford Handbook of Emerging Adulthood. Oxford: Oxford University Press

Perissinotto, C. M., Cenzer, I. S., \& Covinsky, K. E. (2012). Loneliness in older persons: a predictor of functional decline and death. Archives of Internal Medicine, 172(14), 1078-1084. 
EXPLORING AGE AND GENDER DIFFERENCES IN NARCISSISM AND PERFECTIONISM AND THEIR MENTAL-HEALTH CORRELATES

Perlman, D. (1990). Age Differences in Loneliness: A Meta-Analysis. Boston: APA.

Pincus, A. L., \& Lukowitsky, M. R. (2010). Pathological narcissism and narcissistic personality disorder. Annual Review of Clinical Psychology, 6, 421-446.

Pinquart, M., \& Sörensen, S. (2003). Risk factors for loneliness in adulthood and old age--a meta-analysis. Nova Science Publishers.

Qualter, P., Brown, S. L., Rotenberg, K. J., Vanhalst, J., Harris, R. A., Goossens, L., ... \& Munn, P. (2013). Trajectories of loneliness during childhood and adolescence: Predictors and health outcomes. Journal of Adolescence, 36(6), 1283-1293.

Raskin, R. N., \& Hall, C. S. (1979). A narcissistic personality inventory. Psychological Reports, 45(2), 590. https://doi.org/10.2466/pr0.1979.45.2.590

Rhodewalt, F., \& Morf, C. C. (1995). Self and interpersonal correlates of the Narcissistic Personality Inventory: A review and new findings. Journal of Research in Personality, 29(1), 1-23.

Rhodewalt, F., Madrian, J. C., \& Cheney, S. (1998). Narcissism, self-knowledge organization, and emotional reactivity: The effect of daily experiences on self-esteem and affect. Personality and Social Psychology Bulletin, 24(1), 75-87.

Ritchie, H., \& Roser, M. (2020). Mental Health. Published online at OurWorldInData.org. https://ourworldindata.org/mental-health

Roberts, B. W., Edmonds, G., \& Grijalva, E. (2010). It is developmental me, not generation me: Developmental changes are more important than generational changes in narcissism-commentary on Trzesniewski \& Donnellan. Perspectives on Psychological Science, 5, 97-102.

Robinson, J., \& Godbey, G. (1999). Time for life: The surprising ways Americans use their time ( $2^{\text {nd }}$ Ed.). University Park, PA: Pennsylvania State University Press.

Ronningstam, E. (2010). Narcissistic personality disorder: A current review. Current Psychiatry Reports, 12(1), 68-75.

Ronningstam, E. (2011). Narcissistic personality disorder: A clinical perspective. Journal of Psychiatric Practice, 17(2), 89-99.

Rose, P. (2002). The happy and unhappy faces of narcissism. Personality and Individual Differences, 33(3), 379-391.

Roser, M. (2020). Our world in data. https://ourworldindata.org/a-history-of-globalliving-conditions-in-5-charts\#. Accessed on August 19, 2020.

Rothstein, A. (1999). The narcissistic pursuit of perfection. International Universities Press, Inc.

Russ, E., Shedler, J., Bradley, R., \& Westen, D. (2008). Refining the construct of narcissistic personality disorder: Diagnostic criteria and subtypes. American Journal of Psychiatry, 165, 1473-1481.

Russell, D., Peplau, L. A., \& Cutrona, C. E. (1980). The revised UCLA Loneliness Scale: concurrent and discriminant validity evidence. Journal of Personality and Social Psychology, 39(3), 472.

Ryan, R. M., \& Deci, E. L. (2001). On happiness and human potentials: A review of research on hedonic and eudaimonic well-being. Annual Review of Psychology, 52(1), 141-166. 
Ryan, R. M., \& Deci, E. L. (2011). A self-determination theory perspective on social, institutional, cultural, and economic supports for autonomy and their importance for well-being. In Human autonomy in cross-cultural context (pp. 45-64). Springer, Dordrecht.

Ryff, C. D., \& Singer, B. (1998). The contours of positive human health. Psychological Inquiry, 9(1), 1-28.

Ryff, C. D. (1989). Happiness is everything, or is it? Explorations on the meaning of psychological well-being. Journal of Personality and Social Psychology, 57(6), 1069.

Ryff, C. D., \& Keyes, C. L. M. (1995). The structure of psychological well-being revisited. Journal of Personality and Social Psychology, 69(4), 719.

Ryff, C. D., \& Singer, B. (2000). Interpersonal flourishing: A positive health agenda for the new millennium. Personality and Social Psychology Review, 4(1), 30-44.

Ryff, C. D., \& Singer, B. H. (2006). Best news yet on the six-factor model of well-being. Social Science Research, 35(4), 1103-1119.

Sedikides, C., Rudich, E. A., Gregg, A. P., Kumashiro, M., \&Rusbult, C. (2004). Are Normal Narcissists Psychologically Healthy?: Self-Esteem Matters. Personality Processes and Individual Differences, 87(3), 400-416

Sherry, S. B., Hewitt, P. L., Flett, G. L., \& Harvey, M. (2003). Perfectionism dimensions, perfectionistic attitudes, dependent attitudes, and depression in psychiatric patients and university students. Journal of Counseling Psychology, 50(3), 373.

Sherry, S. B., Gralnick, T. M., Hewitt, P. L., Sherry, D. L., \& Flett, G. L. (2014). Perfectionism and narcissism: Testing unique relationships and gender differences. Personality and Individual Differences, 61, 52-56.

Short, M. M., \& Mazmanian, D. (2013). Perfectionism and negative repetitive thoughts: Examining a multiple mediator model in relation to mindfulness. Personality and Individual Differences, 55(6), 716-721.

Smith, M. M., Sherry, S. B., Rnic, K., Saklofske, D. H., Enns, M., \& Gralnick, T. (2016). Are perfectionism dimensions vulnerability factors for depressive symptoms after controlling for neuroticism? A meta-analysis of 10 longitudinal studies. European Journal of Personality, 30(2), 201-212.

Stoeber, J., \& Janssen, D. P. (2011). Perfectionism and coping with daily failures: Positive reframing helps achieve satisfaction at the end of the day. Anxiety, Stress \& Coping, 24(5), 477-497.

Stoeber, J. (2015). How other-oriented perfectionism differs from self-oriented and socially prescribed perfectionism: Further findings. Journal of Psychopathology and Behavioral Assessment, 37(4), 611-623.

Thompson, R. A. (1991). Emotional regulation and emotional development. Educational Psychology Review, 3(4), 269-307.

Thompson, R. A., \& Calkins, S. D. (1996). The double-edged sword: Emotional regulation for children at risk. Development and Psychopathology, 8, 163-182.

Trumpeter, N., Watson, P. J., \& O'Leary, B. J. (2006). Factors within multidimensional perfectionism scales: Complexity of relationships with self-esteem, narcissism, self-control, and self-criticism. Personality and Individual Differences, 41(5), 849860 . 
EXPLORING AGE AND GENDER DIFFERENCES IN NARCISSISM AND PERFECTIONISM AND THEIR MENTAL-HEALTH CORRELATES

Trzesniewski, K. H., Donnellan, M. B., \& Robins, R. W. (2008a). Do today's young people really think they are so extraordinary? An examination of secular trends in narcissism and self-enhancement. Psychological Science, 19, 181-188.

Trzesniewski, K. H., Donnellan, M. B., \& Robins, R. W. (2008b). Is "generation me" really more narcissistic than previous generations? Journal of Personality, 76, 903-918.

Twenge, J. M. (2001). Birth cohort changes in extraversion: A cross-temporal metaanalysis, 1966-1993. Personality and Individual Differences, 30(5), 735-748.

Twenge, J. M., \& Campbell, W. K. (2001). Age and birth cohort differences in self-esteem: A cross-temporal meta-analysis. Personality and Social Psychology Review, 5(4), 321-344.

Twenge, J. M., \& Campbell, W. K. (2003). Isn't it fun to get the respect that we're going to deserve? Narcissism, social rejection, and aggression. Personality and Social Psychology Bulletin, 29(2), 261-272.

Twenge, J. M. (2006). Generation Me: Why today's young Americans are more confident, assertive, entitled - and more miserable than ever before. New York: Free Press.

Twenge, J. M., \& Campbell, S. M. (2008). Generational differences in psychological traits and their impact on the workplace. Journal of Managerial Psychology, 23, 862-877.

Twenge, J. M., Konrath, S., Foster, J. D., Keith Campbell, W., \& Bushman, B. J. (2008). Egos inflating over time: A cross-temporal meta-analysis of the Narcissistic Personality Inventory. Journal of Personality, 76(4), 875-902.

Twenge, J. M., \& Campbell, W. K. (2009). The narcissism epidemic: Living in the age of entitlement. Simon and Schuster.

Twenge, J. M., Campbell, S. M., Hoffman, B. J., \& Lance, C. E. (2010). Generational differences in work values: Leisure and extrinsic values increasing, social and intrinsic values decreasing. Journal of Management, 36, 1117-1142.

Twenge, J. M. (2011). Generational differences in mental health: Are children and adolescents suffering more, or less?. American Journal of Orthopsychiatry, 81(4), 469.

Twenge, J. M., Campbell, W. K., \& Gentile, B. (2012). Generational increases in agentic self-evaluations among American college students. 1966-2009. Self and Identity, 11(4), 409-427.

Twenge, J. M., Campbell, W. K., \& Freeman, E. C. (2012). Generational differences in young adults' life goals, concern for others, and civic orientation, 1966-2009. Journal of Personality and Social Psychology, 102, 1045-1062.

Twenge, J. M., \& Kasser, T. (2013). Generational changes in materialism and work centrality, 1976-2007: Associations with temporal changes in societal insecurity and materialistic role modeling. Personality and Social Psychology Bulletin, 39(7), 883897.

Verhaeghe, P. (2014). What about me? The Struggle for identity in a market based society. London, UK: Scribe Publications.

Veselka, L., Schermer, J. A., \& Vernon, P. A. (2012). The Dark Triad and an expanded framework of personality. Personality and Individual Differences, 53(4), 417-425. 
Victor, C. R., \& Bowling, A. (2012). A longitudinal analysis of loneliness among older people in Great Britain. Journal of Psychology, 146(3), 313-31. doi: 10.1080/00223980. 2011.609572. PMID: 22574423.

Wang, K. T., Yuen, M., \& Slaney, R. B. (2008). Perfectionism. Perfectionism, Depression, Loneliness, and Life Satisfaction: A Study of High School Students in Hong Kong. The Counseling Psychologist, 37(2), 249-274. doi:10.1177/0011000008315975

Watson, P. J., Little, T., Sawrie, S. M., \& Biderman, M. D. (1992). Measures of the narcissistic personality: Complexity of relationships with self-esteem and empathy. Journal of Personality Disorders, 6(4), 434-449.

Watson, P. J., Hickman, S. E., \& Morris, R. J. (1996). Self-reported narcissism and shame: Testing the defensive self-esteem and continuum hypotheses. Personality and Individual Differences, 21(2), 253-259.

WHO (2017). Depression and other common mental disorders - Global health estimates. Geneva: WHO Document Production Services.

WHO (2018). https://www.who.int/news-room/fact-sheets/detail/mentalhealthstrengthening-our-response. Retrieved 12th of April 2020.

Widiger, T. A. (2011). Personality and psychopathology. World Psychiatry, 10, 103-106.

Wittchen, H.U., Jacobi, F., Rehm, J., Gustavsson, A., Svensson, M., Jönsson, B., Steinhausen, H.C. (2011). The size and burden of mental disorders and other disorders of the brain in Europe 2010. European Neuropsychopharmacology, 21(9), 655-679.

Yang, Y. (2008). Social inequalities in happiness in the United States, 1972 to 2004: An age-period-cohort analysis. American Sociological Review, 73(2), 204-226.

Zalpour, K., Shahidi, S., Zarrani, F., Mazaheri, M. A., \& Heidari, M. (2015). Empathy and cognitive emotion regulation in phenotypes of narcissism. Payesh (Health Monitor), 14(2), 239-247.

Zlomke, K. R., \& Hahn, K. S. (2010). Cognitive emotion regulation strategies: Gender differences and associations to worry. Personality and individual Differences, $48(4), 408-413$. 